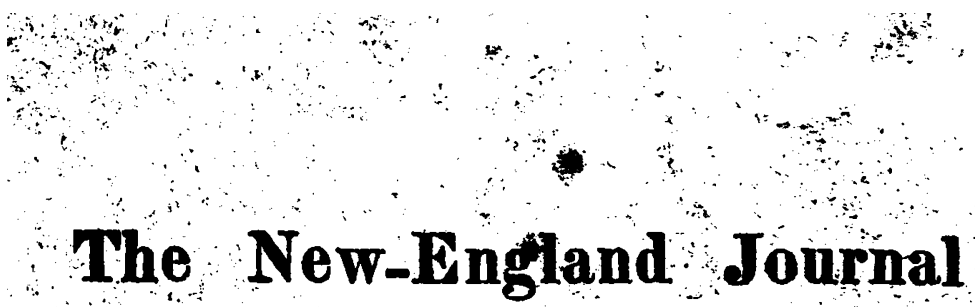

OT

\title{
MEDICINE AND SURGERY:
}

Vol. VIII.

JULY, 1819.

No. III.

Oase of Tic Doulourenx, of obliteration of the brachial ar: 78 tery, and of diseased bones of the leg. By Jasrs Thacher, M.D.

[Communicated for the New-England Journal of Medicine and Surgery.]

7 N our investigations pertaining to the human system, we have to lament the imperfect state of physiological knowledge, Which precludes the ability to define the nature and cause of obscure diseases. Even the inquisitive dissector is too frequentlysbaftled in his attempts to explore the arcana, or secret processes of nature, or detect the origin of that morbid affection which ultimately dissevers the thread of life. From its increàing prevalence, Tic douloureux, or neuralgia, has recentIy arrested the attention of physicians. and been described as 2 disease of the nervous system, exhibiting phenomena of a peculiar character. A detail, relative to the following instance, will serve to show the inveterate and unyielding nature of this novel disease.

Mrs. S. K - a respectable Jady in this town, has at vasious periods been afflicted with attacks of neuralgia. Having employed opium to the fullest extent, aqua ammonie, blisters and other external applications, without deriving any permanent advantage, recourse was had to extract of cicuta, (conium maculatum). This medicine was exhibited for a few days, in doses of two or three grains without effect; but afterwards in increased doses, from 10 to 80 grains an hour, amounting in seyen hours to 400 grains; 200 of which rere. taken during the last two and an half bours. The extract, although of a genuine quality, and administered to such unnanal - Vol. VIII. 
extênt; produced only a slight ğiddiness for a short time, and an abatement of the paroxysims, both in violence and frequency of recurrence; but at the end of twenty-four hours they resumed their accustomed severity, and she lost all confidence in the medicines, but by means of an emetic she obtained a respite. At a subsequent period, the disease raged with such intoleratie violence, in despite of every remedy, that she resolved to subwit to the alternative of the surgical operation of dividing the diseased nerve, and this was accordingly performed in July 1817. The incision was extended to the bone, and the trunk of the suborbitar nerve completely divided, and hopes were; entertained that the long protracted sufferings of the patient were about being brought to a close. The pain, however, continued with more or less severity during the process of healing; after: whichotie enjoyed an exemption for seven or eight months; and was even flattered with a hope that a radical cure would be the result of the operation. In the autumn of 1818 , she was again visited with this distressing complaint, in its most excruciating form, and her sufferings for several weeks were almost insupportable. The pain, which before the operation was confined to the cheek bone, now extended to the forepart and top of the head and side of the face. The spasns occurring so rapidly, that the inlervals of ease were seldom more than four or five minutes; such was the irritability of the nerves, that the least action of the muscles of the face in coughing, chewing, or speaking, would produce a recurrence of the spasms, and excite the keenest anguish. During several weeks, she could not ileep quietly more than five minutes, and seldom more than one hour in forty-eight, although from 80 to 120 drops of laudanum were administered. Under these circumstances; $I$, prged the trial of the extract of stramonium, beginning with one grain; and repeating the dose several times in a day; no sooper was the system fairly under its influence, than the spasms became in a great degree under controul; being rendered less frequent in occurrence, less acute, and shorter in duration. But unfortunately this medicine produced vertigo; blindness, extreme aridity of the mouth and fauces, loss of the power of articulation, great redness of the face, \&c. In addition to these, as she laboured under a troublesone cough, a sensation of cons striction at the breast, and a suppression of expectoration wan evidently induced. Stramonium was now abandoned and the extract of atropa belladonna was substituted, having dertied soute confidence froin reports of its efficacy in this disease. Of this powerful narcotic, two grains were repeated every 4th hour, or one grain every $3 \mathrm{~d}$ hour, till twenty grains were laken; 
this in some degree, blunted the acuteness of the pain and spasms, but excited unpleasant sensations little less intolerable than stramonium, and the use of it was no longer persisted in. By the application of the extract of stramonium over the diseased nerve in the form of plaster, the paroxyвms were inmediately suspended, and on a repetition in $\mathrm{this}$ form, on various occasions the most essential relief was obtained; but after several repetitions, it failed to produce the desired effect. Still however, retaining confidence in the efficacy of this medicine; " it became a desideratum to combine with it some substance that should qualify its narcotic powers, or obviate its deleterious effects, without diminisbing its efticacy as an antispasmodic. For this purpose I resolved to make an experiment with pulv ipecacuanbae, and having combined one grain of this with ope and an half grains extract of stramonium; the experiment was fortunate beyond the most sanguine expectations. The paroxysms immediately yielded under the intluence of two or three pills in a day; no stricture at the chest, nor check of expectoration ensued, and the deleterions effects in general were much less distressing than those of siramonium in its uncombined form. By the employment of this rernedy for two or three days, the paroxysms were totally suspended, and during the last twelve weeks she has been entirely free from the complaint. Although the cure in this instance may not prove permanent and radical, it is a source of infinite satisfaction, should the disease recur, that the result of a happy experiment points to a remedy more deserving of confidence during the dreadful paroxysms, than any other with which we are acquainted. Within the sphere of my information, derived from correspondents and inquiries, more instances can be adduced of successful treatment by means of stramonium, than by any otber remedy ; and by the addition of ipecacuantha, as now ascertained, its deleterious effects may be essentially aneliorated. In this connexion the idea is suggested, whether the deieterious properties of other "uarcotics, as cicuta belladonna, Sc. are not susceptible of correction by a coinbination with ipecacuanba, so as to admit of exhibition in larger than ordinary quantities? In the case of Mrs. K. the cicuta, belladonna, ayua ammoniz, \&c. were administered without that successful result which from favorable reports we had been encouraged to expect. Even the surgical operation of dividing the nerve, disappointed our expectations, and the result has been the same in anather similar instance, which has since occurred. The position will probably be admitted that the division of a single nerve will not ef fect a radical cure, while the various ramifying branches are 
left entire, and when the disease involves the whole nervous aystem, the operation must be deemed altogether ineligible. Neuralgia may, on somé occasions depend on a rheumatic diathesis, there being in some cases an obvious resemblance between,the, acute pain in rheumatism and that of the former disease ; when this can be ascertained, blood-letting, calomel and opium combined, and the volatile tincture of guaiacum in large and repeated doses, will be the preferable remedies. It not unfrequently happens that the condilion of the uervous temperament predisposes to this disease, rendering the patient liable to repeated returus of it, at certain seasons of the $y$ ear, and it may be aggravated by general debility, colds, and a vitiated state of the stomach. In cases of this description, after evacuating the stomach and bowels, those means best calculated to operate on the whole system, as tonic medicines, exercise, and cold bathing, \&c. should be directed, carefully avoiding at the same time all imprudent exposure to the changes of the weather. For the benefit of those who may not be conversant with this malady, it is deemed proper to remark that neuralgic affection is not invariably and exclusively seated in the nerves of the face. Instances are recorded of this complaint being seated * in the nerves of the finger, the thumb, toe, and forearm, in con. sequence of wounds, or from unknown causes.

\section{Oblileration of the brachial Artery.}

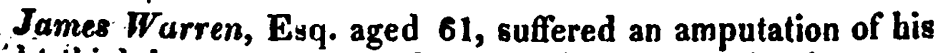
right thigh in consequence of a guu shot wound in the year 1782, since which he has employed a crutch to aid him in walking. In December 1818, he unfortunately receired a fall on the floor, and the right arm being under his body, sustained the force of the blow; the injury however appegred to be very incousiderable, and some time elapsed before any application was made. About three weeks after the accident, I found bim exercised with considerable pain in his arm, regembling rheumatism, but accompanied with a degree of numbness and coldness. Applying my finger to the wrist, no pulsation was. perceptible in either the radial or ulnar artery ; nor' could.I discover any arterial action in any part of the arm. At the other wrist the pulse was full and hard, and considerable fever was indicated. Twelve ounces of blood were taken from the well arm, and vesication and stimulating applicotions, directed to the arm affected. At the expiration of several days symptoms of amendment appeared, the sensations of numberess snd coldness gradually subsided, and by the aid of the cold 
bath and friction, the arm resumed in a considerable degree its natural temperature und ability to action. No emaciation bas ensued; nor much diminution of muscular strength, the veins have become more prominent and turgid, but the extremities of the fingers still continue to be more susceptible of cold than formerly. How long this abolition of pulsation has existed; cannot be ascertained, but that the arteries of the arm have ceased to perform their usual action for more than ten weeks, is a facl, decided by accurate and repeated examination. Can it be supposed that the pressure of the crutch in the axilla, has had the effect of inducing an adbesion of the coats of the artery, and thereby rendering the muscles of the limb nore subsceptible of injury; or shall the obliteration be ascribed solely to the fall? Mr. W. recollects experiencing some degree of numbness and inability of the arm for years past, afier much walking with the crutch, but not to such extent as to indicate any alarming effect. In Cooper's Dictionary of Surgery, when treating of aneurism, it is observed, that "Morand proved that a violent blow may lead to the obliteration of an artery ;" - but he does not explain the principle on which this process is effected. It has been a received doctrine, that when a lighture is applied round an artery, one of its coats is ruptured, by which adhesive inflammation is induced and the artery becomes impervious. But, "Mr. Crampton. proves by various observations and experiments, that the obliteration of an -artery can very certainly be effected independently of the rupture or division of any of its coats," and, "that a very moderate de. gree of irritation applied to the external coat of an artery, aided by a sufficient degree of compression to bring its internal surfaces into contact, is sufficient to effect the obliteration of the canal," and." that it may be effected by such process in a period not exceeding 24 hours." * Whatever in this instance may have been the cause of the impervious condition of the artery, the fact that the limb has since been supplied with arterial blood, adequate to maintain its vitality and strength, is a singular phenomenon, calculated to display the ronderful resources with which nature has endued the animal gyatem.

\section{Disecised bones of the Leg.}

A young man in the lown of Scituate had been for about ten' months afflicted with a diseased state of the bones of his leg. On the anterior part of the tibia a large exostosis or os-

* Nerr-Englaod Medical Journal, Vol, vii. p. 74. 
seous, tumour appeared, and the whole limb from a little above the ankle to the Enee, was daily increasing in size. A hard tumour was discovered in the ham ${ }_{4}$ and the patient began to manifest symptomis of hectic. Conceiving amputation to be indispensable, I performed the operation above the knee, assisted by Drs. Otis, Bayley and Callinore. On examination, the ribia and fibula were found to be united into one solid substance, the bones exhibited no marts of necrosis or caries, but were enlarged to about thrice their natural size; being sawed transversely about midway between the knee, and ankle, the bony substance measured on its longest diameter 4 inches." The tumour in the hasn being dissected out, was found to be a complete'bone, or osseous substance, about three inches long and trojinches broad, entirely disconnected with the femur. Un. acquainted with any theory adequate to account for the phenomena of the growth and diseases of the bones, I hazard no. observations respecting this singular instance.

Plymouth, March 10, 1819.

On the use of the Nitrate of Silver. Bý Jонn WanE, M. p.

[Communicated for the New-England Journal of Medicine and Surgery.]

NHE cases related by Dr. Balfour, in a late number of the 1 Journal, of the internal use of the Nitrate of Silver, in various diseases, appear to be of at least sufficient importanco to invile further attention and claim a more careful investigation; and althongh it is seldom that remedies to which so much is ascribed, ever fully answer the expectations formed of their efficacy, yet any experiments with regard to them are of a certain kind of value, since it is almost as important to exclude useless and superfluous articles from our list of mediçines, as to introduce those which are really possessed of power. As Dr. Balfour does not seem to have been guided by any particular principle in the selection of cases for trial, and as none can be gathered from the result of his experiments, 1 have admipistered it in the same manner, without much regard to the particular state of the system; choosing those patients who did not seem likely to be bepefited by other renedies, or those who had wade use of them nithout advantage. In the relation of cases I observe as nearly as possible the order of time; and those general remarks which have occurred from the use 